\title{
Association between Bone Mineral Density and Fracture Characteristics in the 5th Metatarsal Bone Base Fracture in Elderly for Prediction of Osteoporotic Fracture
}

\author{
Dong-Il Chun', Tae-Hong Min', Jae-Ho Cho², Sung-Hun Won', Jeong-In Shon ${ }^{3}$, Young Yi ${ }^{3}$ \\ 'Department of Orthopaedic Surgery, Soonchunhyang University Seoul Hospital, Soonchunhyang University College of Medicine, Seoul; \\ 2Department of Orthopaedic Surgery, Chuncheon Sacred Heart Hospital, Hallym University, Chuncheon; \\ ${ }^{3}$ Department of Orthopaedic Surgery, Seoul Foot and Ankle Center, Inje University Seoul Paik Hospital, Inje University College of Medicine, \\ Seoul, Korea
}

Corresponding author

Young Yi

Department of Orthopaedic Surgery, Seoul Foot and Ankle Center, Inje University Seoul Paik Hospital, Inje University College of

Medicine, 9 Mareunnae-ro, Jung-gu, Seoul 04551, Korea

Tel: +82-2-2270-0023

Fax: +82-2-2270-0236

E-mail: 20vvin@naver.com

Received: June 10, 2021

Revised: July 5, 2021

Accepted: July 16, 2021
Background: This study aimed to analyze the correlation between bone mineral density (BMD) and the type of 5th metatarsal fracture, as well as to demonstrate whether there is a difference in radiological findings (heel alignment angle [HAA], heel moment arm [HMA], and metatarsus angle) between fracture types. Methods: A total of 87 patients were enrolled in the study and allocated into 3 groups: the Zone 1 group $(\mathrm{N}=36)$, the Zone 2 group ( $\mathrm{N}=33)$, and the Zone 3 group $(\mathrm{N}=18)$. The participants' demographic data, T-scores, existing fracture or osteoporosis medications, and radiologic parameters including HAA, HMA, and metatarsus adductus angle were analyzed and compared. Results: There was a significant difference between the mean age of the participants, with the highest age in the Zone 1 group and the lowest in the Zone 3 group. Regarding the history of concurrent fracture or osteoporosis medications, there was no significant difference between the 3 groups. Similarly, no significant difference was observed between the 3 groups about the BMD values. In contrast, the HAA was statistically significant in all groups with a positive correlation of -8.9 in the Zone 1 group, a negative correlation of 3.55 in the Zone 2 group, and an inverse relationship of 6.1 in the Zone 3 group. The metatarsus adductus angle was significantly higher in the Zone 3 group than the Zone 1 and Zone 2 groups. Conclusions: The location of a 5th metatarsal bone fracture is not significantly associated with BMD. However, mechanical influences, such as hindfoot varus or forefoot adductus, have a significant correlation with fracture types.

Key Words: Bone density · Fracture, bone $\cdot$ Metatarsal bones $\cdot$ Metatarsus · Osteoporosis

\section{INTRODUCTION}

Mineral Research

This is an Open Access article distributed under the terms of the Creative Commons Attribution Non-Commercial License (https://creativecommons.org/licenses/by-nc/4.0/) which permits unrestricted non-commercial use, distribution, and reproduction in any medium, provided the original work is properly cited.

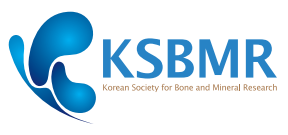


However, opinion differs about whether low-energy trauma-related metatarsal fractures should constitute a reason for bone density assessment. Some studies have shown that patients with a metatarsal fracture are at increased risk of osteoporosis at the spine,[6,7] whereas others have concluded that foot fractures are largely independent of spine bone mineral density (BMD).[8]

Therefore, we authors hypothesized that the correlation between BMD and metatarsal fracture might vary because various fractures occur depending on the location and characteristics of metatarsal bone fractures.

In the past, all 5th metatarsal base fractures were called Jones fractures,[9] but now they are divided into 3 parts depending on the location of the fracture (Fig. 1).[10] First, Zone 1 fracture is a fracture involving the proximal tubercle that results from an avulsion fracture of the long plantar ligament, lateral band of the plantar fascia, or contraction of the peroneus brevis.[11] Zone 2 fracture occurs at the metaphyseal-diaphyseal junction with involvement of the 4th and 5th metatarsal articulation. This injury occurs especially when medio-lateral force is applied to foot while heel is raised and foot is plantar flexed. This Zone is called 'Vascular watershed area' and is known to have a high probability of nonunion. Zone 3 fracture is a fracture of the 5th metatarsal bone diaphysis known as a stress fracture.[12,13] It occurs distal to the 4th and 5th metatarsal articulation, and it has been reported to be related to cavovarus foot deformity or metatarsus adductus deformity.[14] It is assumed that this is due to the tensile force acting on the fracture area.

Therefore, we authors tried to examine 2 aspects in this study. First, to analyze the correlation between BMD values and type of 5th metatarsal fracture. Second, to prove whether there is a difference in radiological paragraphs (heel alignment angle [HAA], heel moment arm [HMA], and metatarsus angle) according to the fracture type.

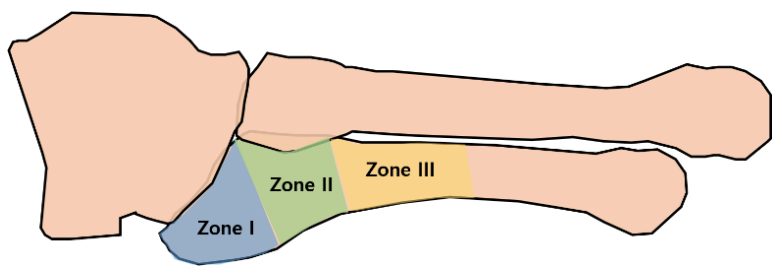

Fig. 1. Three types of metatarsal fracture.

\section{METHODS}

\section{Study group selection}

This retrospective study was evaluated at our institution and approved by the Inje University Seoul Paik Hospital Institutional Review Board (PAIK2018-08-007). Among 428 patients who visited 3 orthopedic department foot and ankle centers for 5 th metatarsal bone base fracture from May 2016 to December 2020, those 55 years of age or older and who underwent BMD were selected. Accordingly, a total of 106 patients were monitored, and patients with high energy trauma injury, with arthritis of the ankle and foot regions, and patients who underwent artificial joint or osteotomy were excluded. Therefore, a total of 87 patients were analyzed. Among them, the Zone 1 group was 36 cases, the Zone 2 group was 33 cases, and the Zone III was 18 cases (Fig. 2).

Thereafter, the BMD values of the 3 groups were compared and analyzed, and whether accompanying fractures or osteoporosis drugs were administered.

Meanwhile, radiological parameters such as HAA, HMA, and metatarsus adductus angle were also analyzed and compared (Fig. 3).

\section{Treatment}

Non-displaced Zone 1 fractures were treated with conservative management [9] and early weight-bearing walking with an orthopedic shoe, Jones bandage dressing, or elastic bandage dressing were recommended.[10,11,1517] However, Zone 1 fractures displaced greater than 3 $\mathrm{mm}$ or comminuted were reduced and operatively fixed using Kirschner wires, small screws, tension band wiring.[9]

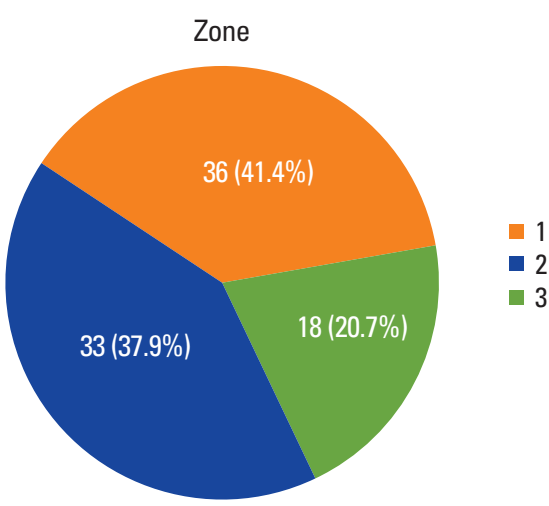

Fig. 2. Three groups of metatarsal fracture. 


\section{JBM}

Since Zone 2 and Zone 3 fractures have a higher rate of delayed union, non-union and refracture, early surgical fixation were applied for faster time to union and return to activity. Tension band wiring, variable pitch tapered crew fixation, and percutaneous bicortical screw fixation were used.[10,12,18,19]

\section{Statistical analysis}

We compared demographic findings, radiologic findings, and BMD according to each Zone group.

Parametric data were expressed as mean \pm standard deviation, and nonparametric data were expressed as median and interquartile ranges. Normality test was performed by Shapiro-Wilk test.

For the differences between the 3 groups, the one-way ANOVA and $\chi^{2}$ test was used for parametric data and the

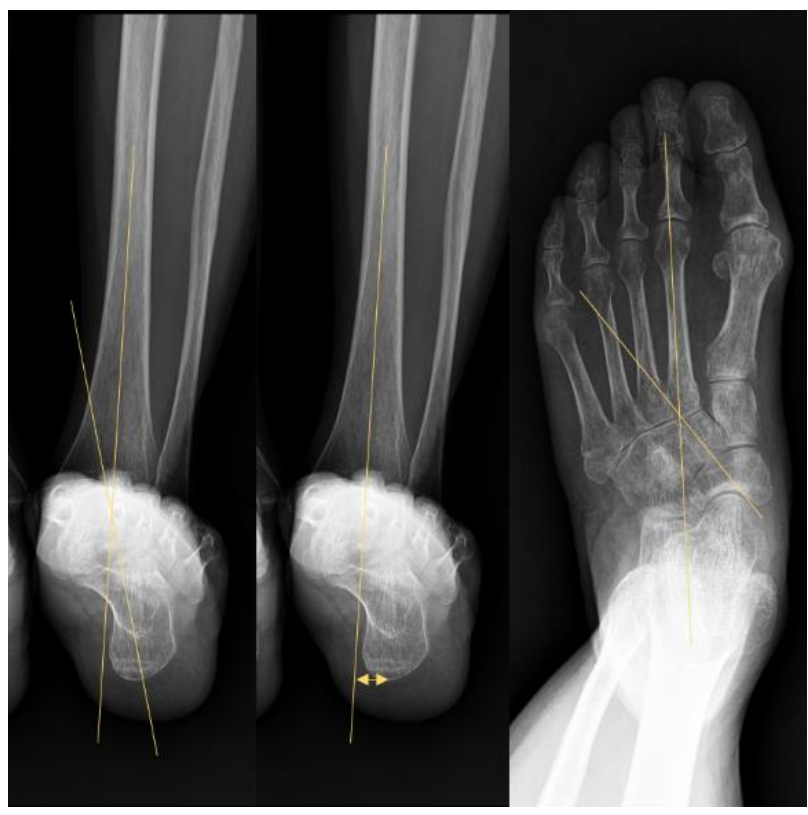

Fig. 3. Radiological parameters.
Kruskal-Wallis test and Fisher's exact test were used for nonparametric data. For all tests, $P$-values of less than 0.05 were considered significant. Statistical analyses were performed using the software package SPSS for Windows version 16.0 (SPSS Inc., Chicago, IL, USA).

\section{Power analysis}

We performed a power analysis corresponding to the primary outcome, the BMD T-score, which was calculated to be $75 \%$ for the lumbar spine and $37.8 \%$ for the femur. On the other hand, our study results show that for the lumbar spine, a total of 95 samples are required to satisfy an effect size of 0.1 , a significance level of 0.05 , and $80 \%$ power. For femur, a total of 258 samples are required under the same conditions. Statistical analyses were performed using $R$ with the pwr package (version 3.6.3; The R Foundation for Statistical Computing, Vienna, Austria).

\section{RESULTS}

The demographic of each group was as follows (Table 1). The mean age of the patient group was the highest in Zone 1 and the lowest in Zone 3, which was statistically significant $(P=0.0035)$. In Zone I and Zone II, female dominance was shown and Zone 3 showed male dominance, but it was not significant. There was no significant difference between the 3 groups in the history of concurrent fractures or osteoporosis medications.

According to the BMD values between each Zone group (Table 2), both the femur and lumbar spine BMD T-scores were highest in Zone 1 and lowest in Zone 3. However, there was no statistical significance in the difference between the 3 groups.

The differences in radiographic features are shown as follows (Table 3).

Table 1. Patients' demographics and the history of concurrent fractures or osteoporosis medications

\begin{tabular}{|c|c|c|c|c|}
\hline & Zone $1(\mathrm{~N}=36)$ & Zone 2 (N=33) & Zone $3(\mathrm{~N}=18)$ & $P$-value \\
\hline Age (yr) & 64 (62 to 68) & 63 (59 to 67) & 60 (58 to 62) & 0.0035 \\
\hline Sex & & & & 0.3053 \\
\hline Male & $15(41.67 \%)$ & $11(33.33 \%)$ & $10(55.56 \%)$ & \\
\hline Female & $21(58.33 \%)$ & $22(66.67 \%)$ & $8(44.44 \%)$ & \\
\hline Accompanying fracture & $6(16.67 \%)$ & $6(18.18 \%)$ & $1(5.56 \%)$ & 0.5425 \\
\hline Osteoporosis medication history & $7(19.44 \%)$ & $8(24.24 \%)$ & $3(16.67 \%)$ & 0.8351 \\
\hline
\end{tabular}

The data is presented as median (range), or number (\%). Stands for $P<0.05$ significant. 
Table 2. Comparison of bone mineral density between 3 groups

\begin{tabular}{lcccc}
\hline & Zone $1(\mathrm{~N}=36)$ & Zone 2 $(\mathrm{N}=33)$ & Zone 3 (N=18) & $P$-value \\
\hline BMD T-score (femur) & $-2.17 \pm 0.49$ & $-2.22 \pm 0.61$ & $-2.27 \pm 0.71$ & 0.6265 \\
BMD T-score (lumbar spine) & $-1.92 \pm 0.65$ & $-2.06 \pm 0.7$ & $-2.25 \pm 0.9$ & 0.3514 \\
\hline
\end{tabular}

The data is presented as mean \pm standard deviation. Stands for $P<0.05$ significant. Comparison of 3 groups using one-way analysis of variance and $\chi^{2}$ test. $\mathrm{BMD}$, bone mineral density.

Table 3. Comparison of radiological parameters between 3 groups

\begin{tabular}{|c|c|c|c|c|c|c|}
\hline & \multirow{2}{*}{$\begin{array}{l}\text { Zone } 1 \\
(\mathrm{~N}=36)\end{array}$} & \multirow{2}{*}{$\begin{array}{l}\text { Zone } 2 \\
(\mathrm{~N}=33)\end{array}$} & \multirow{2}{*}{$\begin{array}{l}\text { Zone } 3 \\
(N=18)\end{array}$} & \multirow[b]{2}{*}{$P$-value ${ }^{\mathrm{a})}$} & \multicolumn{2}{|c|}{ Post-hoc $(P \text {-value })^{b)}$} \\
\hline & & & & & $\begin{array}{l}\text { Zone } 1 \text { vs. } \\
\text { Zone } 2\end{array}$ & $\begin{array}{c}\text { Zone } 1 \text { vs. } \\
\text { Zone } 3\end{array}$ \\
\hline HAA & $-2.2(-3.6$ to 1.7$)$ & 2 (-3.8 to 3.08$)$ & 2.6 (-0.3 to 3.95$)$ & 0.0316 & 0.5307 & 0.0172 \\
\hline HMA & $-8.9(-12.05$ to 3.9$)$ & $3.55(-11.43$ to 8.43$)$ & $6.1(-1.65$ to 8.45$)$ & 0.018 & 0.2993 & 0.0097 \\
\hline Metatarsus adductus angle & 20.15 (17.65 to 22.72) & 20.1 (16.8 to 26.8) & 28.85 (21.42 to 32.1$)$ & 0.012 & 1.0000 & 0.0106 \\
\hline
\end{tabular}

The data is presented as mean (range). Stands for $P<0.05$ significant. Comparison of 3 groups using one-way analysis of variance and $\chi^{2}$ test.

a) $P$-value was calculated by Kruskal-Wallis test.

b) $P$-value were calculated by Dunnett's method using Bonferroni's correction.

HAA, heel alignment angle; HMA, heel moment arm.

The HAA had an average value of -2.2 in Zone 1, 2 in Zone 2, and 2.6 in Zone 3, which was statistically significant $(P=0.0316)$. Zone 1 showed a positive correlation of -8.9, Zone 23.55 , and Zone 36.1 , a statistically significant difference $(P=0.018)$. The metatarsus adductus angle was 28.85 in Zone 3, which was higher than in Zone 1 (20.15) and Zone 2 (20.1), which was also statistically significant $(P=0.012)$. In the post hoc test, significant correlations were observed between Zone 1 and Zone 3 in both HAA and HMA and metatarsus adductus angle.

\section{DISCUSSION}

The 5th metatarsal fracture is the most common fracture in metatarsal bone. The peroneus brevis tendon attaches to the dorsolateral aspect of the tuberosity at the base of the 5th metatarsal bone, the peroneus tertius tendon attaches to the dorsal side of the metaphysis, the lateral band of plantar fascia attach to plantar aspect of tuberosity and the interosseous ligament to between the base of 4 th and 5th metatarsal bone. The tuberosity is supplied by the metaphyseal artery. The nutrient artery enters the bone marrow cavity from the diaphysis, then divided into a branch running distally and a branch running retrograde to provide blood supply to a proximal metaphyseal-diaphyseal junction. So, vascular watershed area exists in metaphyseal-diaphyseal junction, which accounts for the higher risk of delayed union and nonunion of fractures in this region. $[20,21]$

There have been various studies on the correlation between 5th metatarsal base fracture and osteoporosis.[7,22] Varenna et al. [6] reported an association between low Tscore level at L-spine and metatarsal base fracture. Guler and Cerci [23] analyzed Zone 3 stress fracture of 5th metatarsal base in premenopausal and postmenopausal women. It was reported that serum levels of vitamin D were lower in postmenopausal women, and the risk of stress fracture was higher in this regard.[23]

However, some studies have shown that there is no significant correlation between metatarsal base fracture and osteoporosis. Bridges and Ruddick [24] reported that patients with metatarsal fracture have a normal age-matched BMD. The reason why the results of previous research dealing with the relationship between osteoporosis and the occurrence of 5th metatarsal bone fracture are different, we thought that the location of the 5th metatarsal bone fracture could act as a variable. Accordingly, we compared the difference in BMD according to each Zone, and this is the first study to confirm the difference in variables according to the metatarsal base fracture area.

Although there was no statistical significance in our results, the BMD values according to each Zone group were relatively highest in Zone 1 and lowest in Zone 3. It was judged that this was because, compared to Zone 1 frac- 


\section{JBM}

tures, which had many avulsion fractures due to relatively high energy, Zone 3 had more stress fractures in the metatarsal bone diaphysis area. However, this may be due to the small number of samples, so further studies with a larger sample are needed to verify a more accurate correlation.

Also, a previous study by Pradhan et al. [25] reported Zone 3 atypical fracture associated with long-term use of bisphosphonates and that long-term use of osteoporosis drugs can cause atypical metatarsal fractures, so it is necessary to take medical history closely. Also, in our study, Zone 3 metatarsal fracture was observed in patients with osteoporosis who took long-term bisphosphonate therapy. However, looking at the overall rate, the rate of taking osteoporosis drugs was rather high in Zone 2, and there was no statistical significance. However, this result is because other osteoporosis drugs such as selective estrogen receptor modulator as well as bisphosphonate were included in the group study. It was also inferred that the proportion of stress fractures other than bisphosphonate-induced stress fractures was more common in Zone 3.

Next, there were studies about the occurrence of 5th metatarsal bone fracture according to the foot alignment angle. Fleischer et al. [14] described that adducted forefoot posture and varus heel posture act as risk factors for Jones fracture by increasing the force on the 5th metatarsal bone. Raikin et al. [19] reported that $90 \%$ of patients diagnosed with Jones fracture had hindfoot varus, and $0 \%$ of refractures were observed when a lateral heel wedge or forefoot post insert was inserted after surgery. Our present study also showed the same trend as previous studies. Furthermore, in hindfoot alignment, the more proximal the fracture occurred, the higher the probability that the heel had a varus posture. We thought that this is because the area where the stress concentration is applied to the 5 th metatarsal bone varies depending on the posture of the heel. The more the heel takes a varus posture, the more the HMA is tilted to the medial and becomes larger, and the proximal of the 5th metatarsal bone is strengthened (Fig. 4).

In the case of metatarsus adductus, Fishco et al. [26] reported in a previous study that the presence of metatarsus adductus increased pedobarograph foot pressure in the lateral midfoot area. Similarly, in our study, the metatarsus adductus angle was significantly higher in Zone 3 than in Zone 1 and Zone 2, indicating that strain was relatively applied to the distal area of the 5th metatarsal bone in the
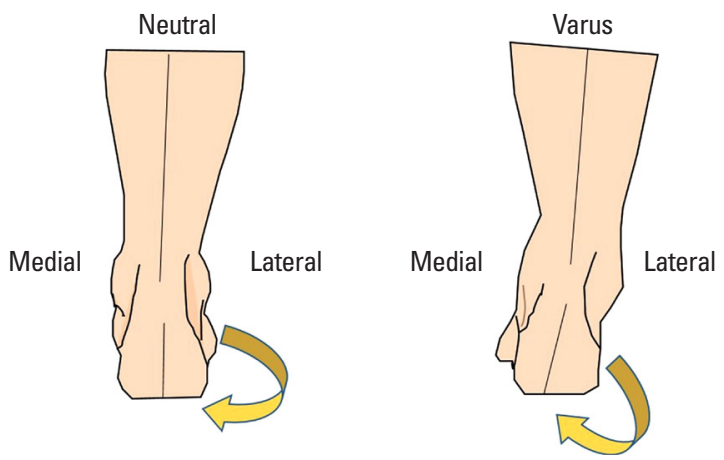

Fig. 4. Changes in the location of stress concentration according to changes in heel alignment.

presence of metatarsus adductus.

However, our study also has some drawbacks. First, the sample size of Zone 3 was small, which made more accurate analysis difficult. This may be because Zone 3 fracture is relatively rare compared to Zone 1 and Zone 2 . Therefore, it is necessary to analyze each Zone group further later. Second, each patient's BMD was measured only on the femur and lumbar spines. Since this study is an analysis of foot fractures, measurements from tarsal bones such as calcaneus may reflect more accurate results. However, due to the technical problem of this medical institution, it was not possible to measure in the relevant area. Finally, there is a disadvantage that information on more diverse demographics, such as body mass index, could not be investigated.

Despite these shortcomings, this study is the first to compare the characteristics of fractures occurring in each Zone in the 5th metatarsal bone fracture. Through this, it was found that mechanical properties such as foot alignment angle were more important than bone quality such as patient's BMD in the occurrence of fractures occurring in each Zone.

\section{CONCLUSION}

In the occurrence of 5th metatarsal bone fracture, the difference according to the location of each Zone does not have a large effect on the patient's BMD, but mechanical influences such as hindfoot varus or forefoot adductus act greatly. 


\section{DECLARATIONS}

\section{Funding}

This work was supported by the 2019 Inje University research grant.

\section{Ethics approval and consent to participate}

This retrospective study conformed to the ethical guidelines of the 1975 Declaration of Helsinki and was approved by the Institutional Review Board (IRB) of the Inje University Seoul Paik Hospital (IRB no. PAIK2018-08-007).

\section{Conflict of interest}

No potential conflict of interest relevant to this article was reported.

\section{ORCID}

Dong-II Chun

Tae-Hong Min

Jae-Ho Cho

Sung-Hun Won

Young Yi https://orcid.org/0000-0001-7255-8984

https://orcid.org/0000-0003-2832-1263

https://orcid.org/0000-0001-8680-4680

https://orcid.org/0000-0002-5471-7432

https://orcid.org/0000-0002-5022-4251

\section{REFERENCES}

1. Cummings SR, Melton LJ. Epidemiology and outcomes of osteoporotic fractures. Lancet 2002;359:1761-7. https:// doi.org/10.1016/s0140-6736(02)08657-9.

2. Latimer N, Lord J, Grant RL, et al. Cost effectiveness of COX 2 selective inhibitors and traditional NSAIDs alone or in combination with a proton pump inhibitor for people with osteoarthritis. BMJ 2009;339:b2538. https://doi.org/10.1136/ bmj.b2538.

3. Miller J. The Scottish Intercollegiate Guidelines Network (SIGN). Br J Diabetes Vasc Dis 2002;2:47-9.

4. Black DM, Cummings SR, Karpf DB, et al. Randomised trial of effect of alendronate on risk of fracture in women with existing vertebral fractures. Fracture Intervention Trial Research Group. Lancet 1996;348:1535-41. https://doi.org/ 10.1016/s0140-6736(96)07088-2.

5. McClung MR, Geusens P, Miller PD, et al. Effect of risedronate on the risk of hip fracture in elderly women. Hip Intervention Program Study Group. N Engl J Med 2001;344: 333-40. https://doi.org/10.1056/nejm200102013440503.

6. Varenna M, Binelli $L$, Zucchi F, et al. Is the metatarsal frac- ture in postmenopausal women an osteoporotic fracture? A cross-sectional study on 113 cases. Osteoporos Int 1997; 7:558-63. https://doi.org/10.1007/bf02652562.

7. Tomczak RL, VanCourt R. Metatarsal insufficiency fractures in previously undiagnosed osteoporosis patients. J Foot Ankle Surg 2000;39:174-83. https://doi.org/10.1016/s10672516(00)80019-8.

8. Seeley DG, Kelsey J, Jergas M, et al. Predictors of ankle and foot fractures in older women. The Study of Osteoporotic Fractures Research Group. J Bone Miner Res 1996;11:134755. https://doi.org/10.1002/jbmr.5650110920.

9. Jones R. 1. Fracture of the base of the fifth metatarsal bone by indirect violence. Ann Surg 1902;35:697-700.2.

10. Quill GE, Jr. Fractures of the proximal fifth metatarsal. Orthop Clin North Am 1995;26:353-61.

11. Egol K, Walsh M, Rosenblatt K, et al. Avulsion fractures of the fifth metatarsal base: a prospective outcome study. Foot Ankle Int 2007;28:581-3. https://doi.org/10.3113/ fai.2007.0581.

12. Cheung CN, Lui TH. Proximal fifth metatarsal fractures: Anatomy, classification, treatment and complications. Arch Trauma Res 2016;5:e33298. https://doi.org/10.5812/atr. 33298.

13. Kadel NJ, Teitz CC, Kronmal RA. Stress fractures in ballet dancers. Am J Sports Med 1992;20:445-9. https://doi.org/ 10.1177/036354659202000414.

14. Fleischer $A E$, Stack R, Klein EE, et al. Forefoot adduction is a risk factor for Jones fracture. J Foot Ankle Surg 2017;56: 917-21. https://doi.org/10.1053/j.jfas.2017.04.017.

15. Gray AC, Rooney BP, Ingram R. A prospective comparison of two treatment options for tuberosity fractures of the proximal fifth metatarsal. Foot (Edinb) 2008;18:156-8. https: //doi.org/10.1016/j.foot.2008.02.002.

16. Vorlat P, Achtergael W, Haentjens P. Predictors of outcome of non-displaced fractures of the base of the fifth metatarsal. Int Orthop 2007;31:5-10. https://doi.org/10.1007/ s00264-006-0116-9.

17. Wiener BD, Linder JF, Giattini JF. Treatment of fractures of the fifth metatarsal: a prospective study. Foot Ankle Int 1997;18:267-9. https://doi.org/10.1177/1071100797018 00504.

18. Kelly IP, Glisson RR, Fink C, et al. Intramedullary screw fixation of Jones fractures. Foot Ankle Int 2001;22:585-9. https: //doi.org/10.1177/107110070102200710.

19. Raikin SM, Slenker N, Ratigan B. The association of a varus 
hindfoot and fracture of the fifth metatarsal metaphysealdiaphyseal junction: the Jones fracture. Am J Sports Med 2008;36:1367-72. https://doi.org/10.1177/036354650831 4401.

20. Dameron TB, Jr. Fractures and anatomical variations of the proximal portion of the fifth metatarsal. J Bone Joint Surg Am 1975;57:788-92.

21. Kavanaugh JH, Brower TD, Mann RV. The Jones fracture revisited. J Bone Joint Surg Am 1978;60:776-82.

22. Hasselman $C T$, Vogt MT, Stone $K L$, et al. Foot and ankle fractures in elderly white women. Incidence and risk factors. J Bone Joint Surg Am 2003;85:820-4. https://doi.org/ 10.2106/00004623-200305000-00008.

23. Guler $\mathrm{O}$, Cerci MH. A comparative overview of metatarsal stress fractures in premenopausal and postmenopausal women: our single-centre experience with eighty-one patients. Int Orthop 2020;44:2407-12. https://doi.org/10.1007/ s00264-020-04528-7.

24. Bridges MJ, Ruddick S. Are metatarsal fractures indicative of osteoporosis in postmenopausal women? Foot Ankle Spec 2011;4:271-3. https://doi.org/10.1177/19386400114 12953.

25. Pradhan P, Saxena V, Yadav A, et al. Atypical metatarsal fracture in a patient on long term bisphosphonate therapy. Indian J Orthop 2012;46:589-92. https://doi.org/10.4103/ 0019-5413.101048.

26. Fishco WD, Ellis MB, Cornwall MW. Influence of a metatarsus adductus foot type on plantar pressures during walking in adults using a pedobarograph. J Foot Ankle Surg 2015;54:449-53. https://doi.org/10.1053/j.jfas.2014.11.007. 
